\title{
Recruiting and Baseline of the HIV-HEART Study: A Prospective, Multicenter Trial to Analyze Cardiac Diseases in HIV-Infected Patients
}

\author{
Till Neumann ${ }^{*}, 1$, Andreas Sundermeyer ${ }^{1}$, Stefan Esser ${ }^{2}$, Anja Potthoff ${ }^{3}$, Martin Hower ${ }^{4}$, \\ Ingulf Becker-Boost ${ }^{5}$, Birgit Ross ${ }^{2}$, Robert Jablonka ${ }^{2}$, Katrin Neuhaus ${ }^{1}$, Anja Neumann ${ }^{6}$, \\ Nico Reinsch ${ }^{1}$, Rolf Wachter ${ }^{7}$, Thomas Müller-Tasch ${ }^{8}$, Felix Mehrhof ${ }^{9}$, Christiane Prettin ${ }^{10}$, \\ Götz Gelbrich $^{10}$, Bernhard Maisch ${ }^{11}$, Norbert Brockmeyer ${ }^{3}$, Jürgen Wasem ${ }^{6}$, Rainer Dietz ${ }^{9}$ and \\ Raimund Erbel ${ }^{1}$ for the HIV-HEART Study Investigative Group on Behalf of the German \\ Competence Network of Heart Failure and German Competence Network for HIV/AIDS
}

Departments of Cardiology ${ }^{1}$, and Dermatology ${ }^{2}$, University Hospital Essen, the Department of Dermatology ${ }^{3}$, University Hospital Bochum, HIV-Outpatient Clinic, Dortmund ${ }^{4}$ and Duisburg, the Alfried Krupp von Bohlen und Halbach Foundation-Institute for Health Systems Management ${ }^{6}$, University of Duisburg-Essen, the Department of Cardiology ${ }^{7}$, University Hospital Göttingen, Department of Psychosomatic and General Internal Medicine ${ }^{8}$ University Hospital Heidelberg, the Department of Cardiology9, Charite, University Hospital Berlin, Clinical Trials Centre Leipzig, University of Leipzig ${ }^{10}$, University of Leipzig, the Department of Cardiology ${ }^{11}$, University Hospital Marburg, Germany

\begin{abstract}
Background: An increased life span and the amount of cardiovascular risk factors necessitate a closer look on cardiac diseases in the population of human immunodeficiency virus (HIV) - infected subjects. Therefore, we launched a cardiology driven study analyzing HIV-associated diseases supported by the federal ministry of research.

Methods: The HIV-HEART (HIV-infection and HEART disease) study is a prospective and multicenter cohort study performed in an urban area. The study comprehends standardized non-invasive cardiology tests of cardiac diseases, such as laboratory parameter, electrocardiogram, echocardiography and an endurance testing by a six-minute walk test.

Results: In a 20 month recruiting period $802 \mathrm{HIV-infected} \mathrm{patients} \mathrm{(age:} \mathrm{44,2} \pm$ 10,3 years; male: 83,4\%) were included into the HIV-HEART Study. Duration of HIV-infection since initial diagnosis was 7,6 $\pm 5,8$ years. Virus load was in $65,6 \%$ less than 50 copies $/ \mathrm{ml}$ and CD4 - cell count $(508,8 \pm 300,6$ cells $/ \mu 1)$ was more than 500 cells $/ \mu 1$ in $42,6 \%$. A reduced CD4 - cell count between 200 and 499 cells/ $\mu 1$ or less than 200 cells/ $\mu 1$ was present in $45 \%$ and $12,4 \%$, respectively. Of all participants, $85,2 \%$ received antiretroviral therapy, most of these patients NRTIs (96,8\%), followed by PIs $(48,5 \%)$, and NNRTIs $(45,7 \%)$.

Conclusions: The characteristics of the HIV-HEART Study cohort are comparable to other national or international cohort registers on HIV-infected persons, performed in industrialized countries. Therefore, the HIV-HEART Study will be able to yield reliable data on the performance of HIV-associated diseases. (Clinical Trials NCT01119729).
\end{abstract}

Keywords: Cardiac diseases, human immunodeficiency virus, antiretroviral therapy, atherosclerosis.

\section{INTRODUCTION}

Patients with a human immunodeficiency virus (HIV) infection feature an increased life expectancy in the era of antiretroviral therapy. A reduction of opportunistic infections and a better immune system diminished mortality in this patient population. As a result of a longer life span, an increase of concomitant chronic diseases has been observed [1].

In particular, cardiac disorders occur more frequently in HIV-infected patients. These diseases are the leading cause of death and hospitalization in most industrial countries,

*Address correspondence to this author at the Department of Cardiology, University of Duisburg-Essen, Medical School, Hufelandstr. 55, D-45122 Essen, Germany; Tel: ++49 (0)201 723 4806; Fax: ++49 (0)201 723 5488; E-mail: till.neumann@uni-essen.de 
HIV-infected subjects. All major aspects of the HIV-HEART Study, including design, inclusion and exclusion criteria, diagnostic techniques and questionnaires, have been presented previously [3]. To increase the quality of the trial a pilot study including over 100 patients was performed in advance.

The present study was designed as a multicenter trial. Therefore, a local network has been founded composed of physicians specialized in the diagnostic and treatment of HIV-infected patients. This network included medical practices, health care centers, and outpatient departments.

The focus of the HIV-HEART Study rests on cardiac diseases in HIV-infected outpatients without acute disorders. Hence, exclusion criteria were instable cardiovascular status within the last four weeks prior to the screening visit or current hospitalization. Furthermore, patients with an inability or unwillingness to give informed consent to participate in the study, an age less than 18 years, or pregnancy were excluded from the study. All end points of the study had been previously described [3]. Beside economic aspects and quality of life, the major end points were prevalence and etiology of cardiovascular diseases in HIV-infected subjects.

A targeted assessment of medical history and physical examination was performed in participants. All non-invasive tests and physical examinations of the present study were explained and performed during the initial visit or within the following week. Altogether, physical and non-invasive tests took not more than 90 minutes for each individual. In addition to non-invasive tests, questionnaires covering a comprehensive risk-assessment were filled. For the quality of life assessment standardized questionnaires (SF-36 and EQ-5D) have been used.
Blood was drawn for comprehensive laboratory tests. Subsequent, heart rate and blood pressure measurements, resting electrocardiogram (ECGs), a health condition test (six-minute walk test) and a comprehensive and standardized transthoracic echocardiography have been performed. The examinations were achieved in compliance with the standing operating procedures (SOPs) of the German Heart Failure Network.

\section{Statistics}

Statistical analysis was performed by the statistical package SPSS Version 17.0 (SPSS Inc.). Variables were presented as means and standard deviation. In addition, mean and interquartile range (IQR) from $25 \%-75 \%$ quartile are presented as well as the whole range including minimum and maximum values.

\section{Ethical Considerations}

The protocol was approved by the Institutional Review Board of our center and was performed in accordance with institutional guidelines and the Declaration of Helsinki. All patients submitted a written informed consent before entering the study.

\section{RESULTS}

\section{Recruiting}

The recruiting in the time period between September 2004 and May 2006 is presented in Fig. (1). During the whole recruiting period, a nearly linear inclusion of patients could be achieved.

All patients, who fulfilled the inclusion criteria and were requested to participate at the HIV-HEART Study, were registered. Only a minority of 67 subjects (48 male, 19

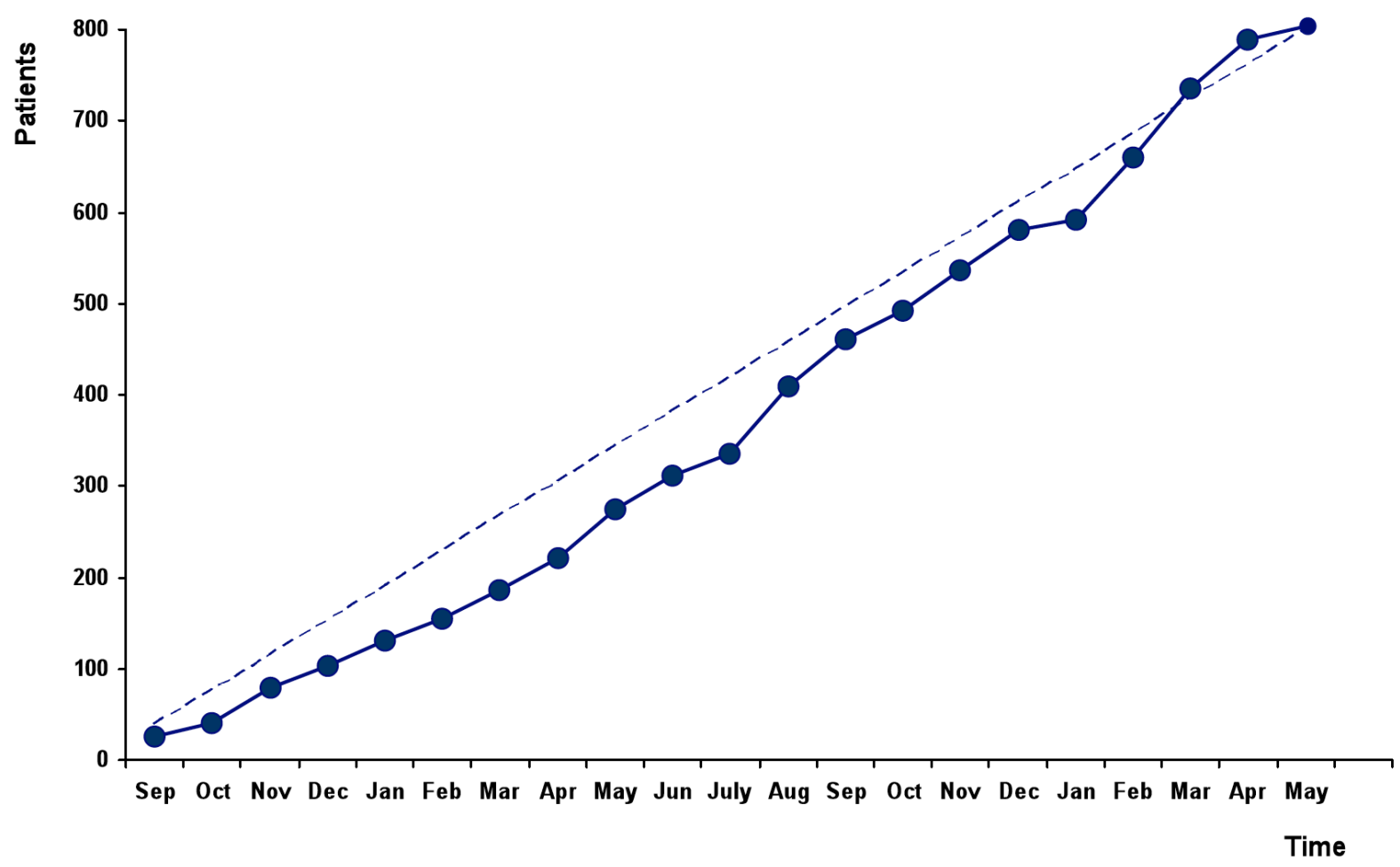

Fig. (1). Recruiting of patients into the HIV-HEART study between September 2004 and Mai 2006. 


\section{Age of the HIV-HEART study participants}

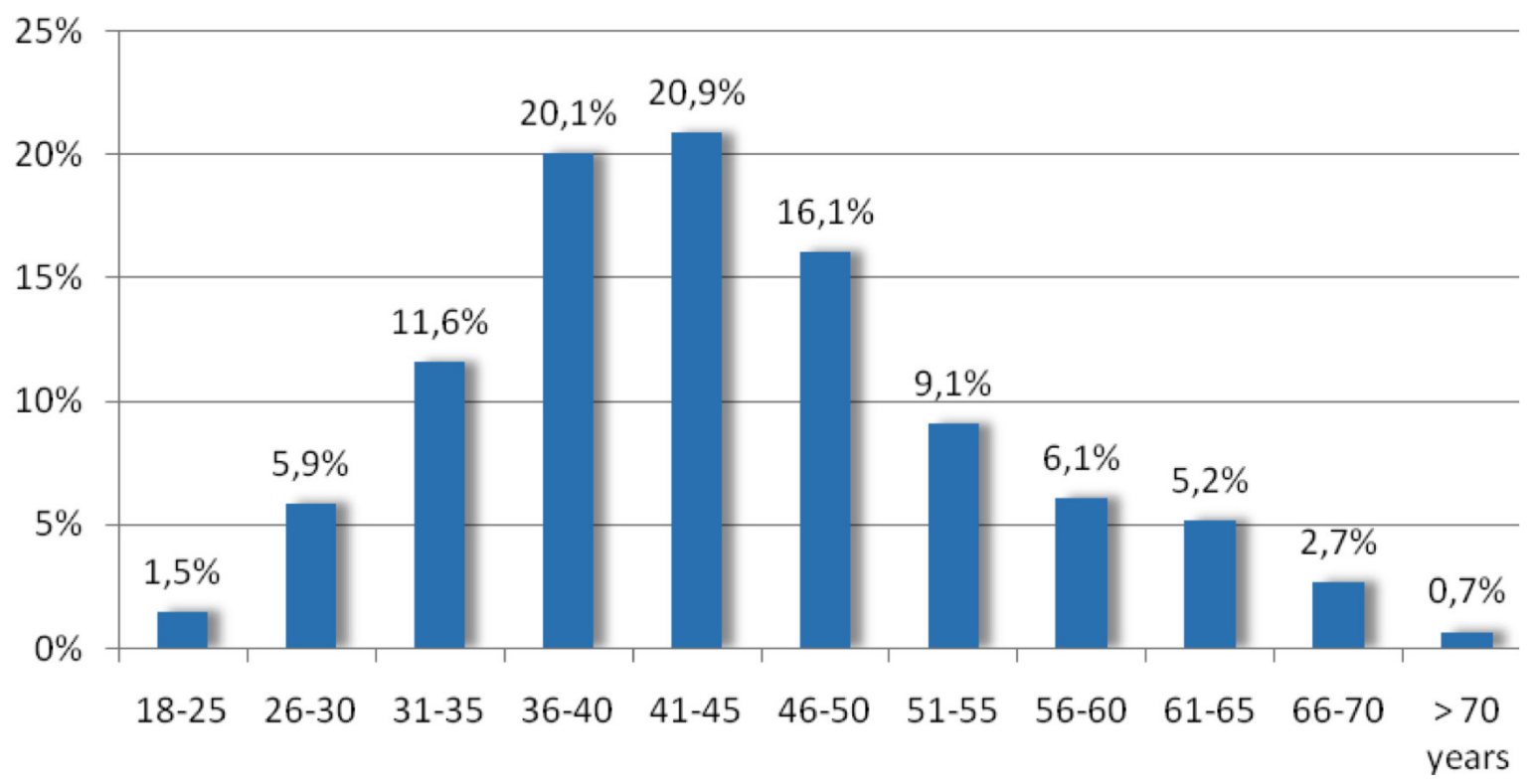

Fig. (2). Age distribution of patients in the HIV-HEART study.

female) did not assent to the study. Frequent motives to negate participation were a missing of interest or time due to professional and private reasons. The demographic data of these patients were documented. From those persons who had been informed about the study and asked to contribute, more than $92 \%$ assent to patient information and support the study.

\section{Baseline Characteristics}

From the included 802 participants of the HIV-HEART Study $83,4 \%$ were male. The mean age in this population was 44, $2 \pm 10,3$ years [Median: 43y; IQR: 37-50y] with a range of 21 up to 75 years. The age distribution in this population is presented in Fig. (2).

Patients in the HIV-HEART Study had a size of 176, $3 \pm$ 9, $1 \mathrm{~cm}$ [Median $177 \mathrm{~cm}$; IQR 170-182 cm] and a body weight of 75, $1 \pm 13,4 \mathrm{~kg}$ [Median 74, $0 \mathrm{~kg}$; IQR 66-82 kg]. These parameters yield to a BMI of $24,1 \pm 3,7 \mathrm{~kg} / \mathrm{m}^{2}$ [Median 23, $8 \mathrm{~kg} / \mathrm{m}^{2}$; IQR 21, 6-26, $0 \mathrm{~kg} / \mathrm{m}^{2}$ ] with a whole range of 14,9 to $40,7 \mathrm{~kg} / \mathrm{m}^{2}$. Further details about graduation of BMI by UN-Classification [4] are presented in Table 1.

Table 1. Body Mass Index (BMI) in HIV-Infected Patients

\begin{tabular}{|c|c|c|}
\hline & BMI $\left[\mathbf{k g} / \mathbf{m}^{2}\right]$ & \%-Value \\
\hline \hline Underweight & $<18,5$ & $2,5 \%$ \\
\hline Normal weight & $18,5-24,99$ & $63,8 \%$ \\
\hline Praeadipositas & $25,0-29,99$ & $26 \%$ \\
\hline Adipositas I & $30,0-34,99$ & $6,3 \%$ \\
\hline Adipositas II & $35,0-39,99$ & $1,3 \%$ \\
\hline Adipositas III & $\geq 40,0$ & $0,3 \%$ \\
\hline
\end{tabular}

Graduation of HIV-infected subjects in the HIV-HEART Study following the World Health Organization Classification of body mass index (BMI).
The mean blood pressure in the present cohort was systolic 128, $4 \pm 20,7 \mathrm{mmHg}$ and diastolic $83,2 \pm 12,4$ $\mathrm{mmHg}$. In addition to blood pressure, the heart rate was determined by all subjects before clinical examination. For the whole study population, the mean heart rate was $70,6 \pm$ 12, 2 beats per minute [Median $69 \mathrm{bpm}$; IQR 62-78 bpm]. About one quarter $(22,5 \%)$ of the HIV-infected patients had pathologic heart rate values of bradycardia with $<60 / \mathrm{min}$ $(16.3 \%)$ or tachycardia with $>90 / \min (6.2 \%)$.

\section{Characteristics of HIV-Infection}

At the date of initial HIV-diagnosis, the age of the participants was $36,5 \pm 10,7$ years. Hence, the HIV-infection was known for 91, $6 \pm 69$ months $(=7,6 \pm 5,8$ years $)$ when patients were included into the trial. The duration of HIVinfection since initial diagnosis is displayed in Fig. (3). As presented in Fig. (4), the majority of patients $(n=477)$ of our cohort was infected by the risk of MSM (man-having-sexwith-man).

Of our study population $85,2 \%$ were antiretroviral treated. Overall virus load was $33419 \pm 71827$ (Median: 6065) copies per ml, virus load of untreated patients was $45294 \pm$ 85027 (Median: 20873) copies per $\mathrm{ml}$. Virus load concentration are presented in Fig. (5).

CD4 - cell count, as a second prognostic relevant parameter of HIV-infection, was $508,8 \pm 300,6$ cells $/ \mu 1$ [Median 460 cells/ $\mu$ 1, IQR: 301, 0-652, 8 cells/ $\mu 1]$. CD4 cell count was more than 500 cells $/ \mu 1$ in $42,6 \%$. A reduced CD 4 - cell count between 200 and 499 cells/ $\mu 1$ or less than 200 cells/ $\mu 1$ was present in $45 \%$ and $12,4 \%$, respectively.

The CD4/CD8 ratio was $0,62 \pm 0,53$ and the percentage of CD4-cells was $25,5 \pm 11,2 \%$. Of all included subjects 99 , $9 \%$ were infected with the HIV-type 1; only one patient had an infection with HIV-type 2. The CDC-Classification of the included patients is presented in Fig. (6). More than 30\% of 


\section{Duration of HIV-infection}

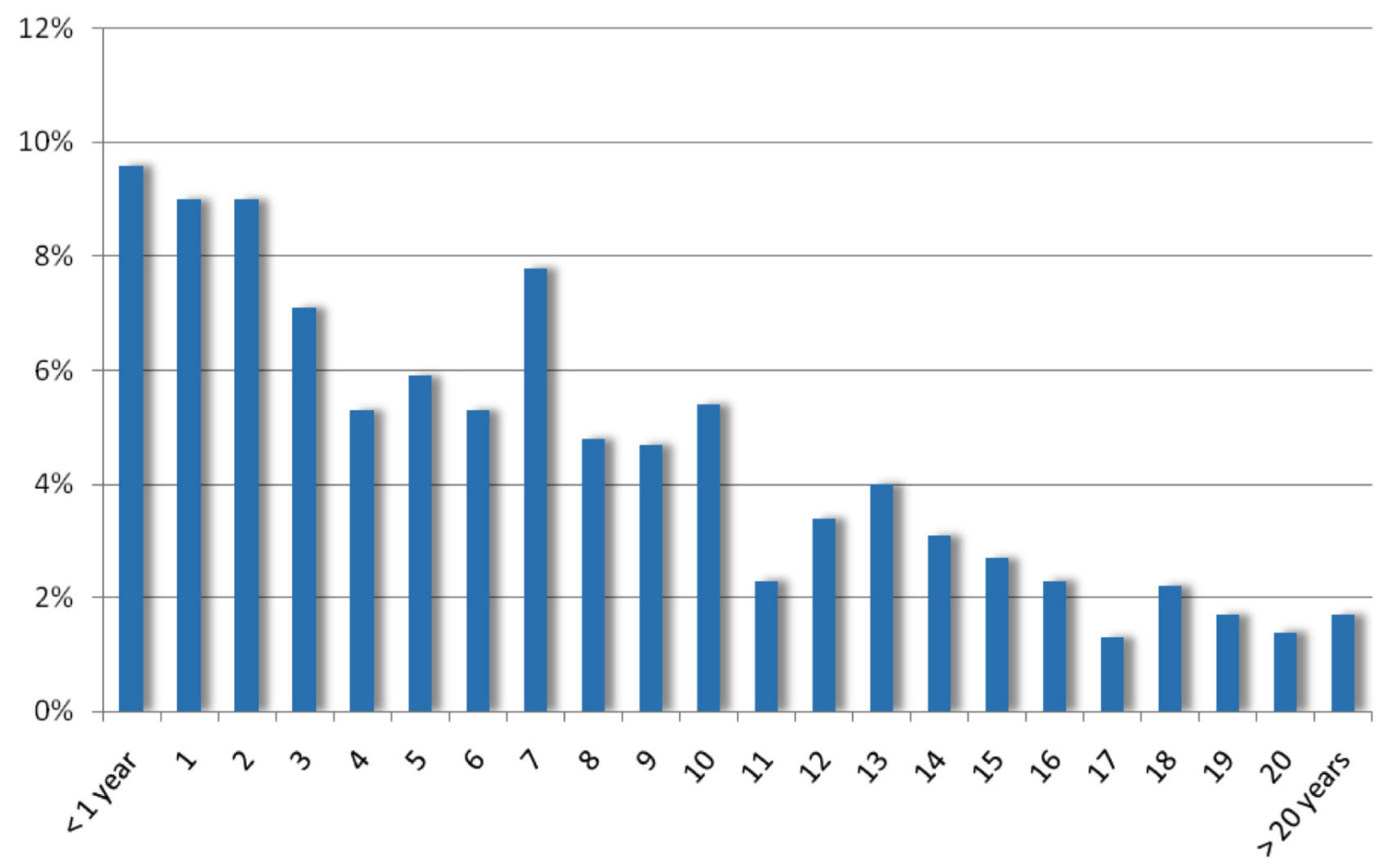

Fig. (3). Duration between the initial diagnosis of HIV-infection and the inclusion into the HIV-HEART study.

\section{Method of infection}

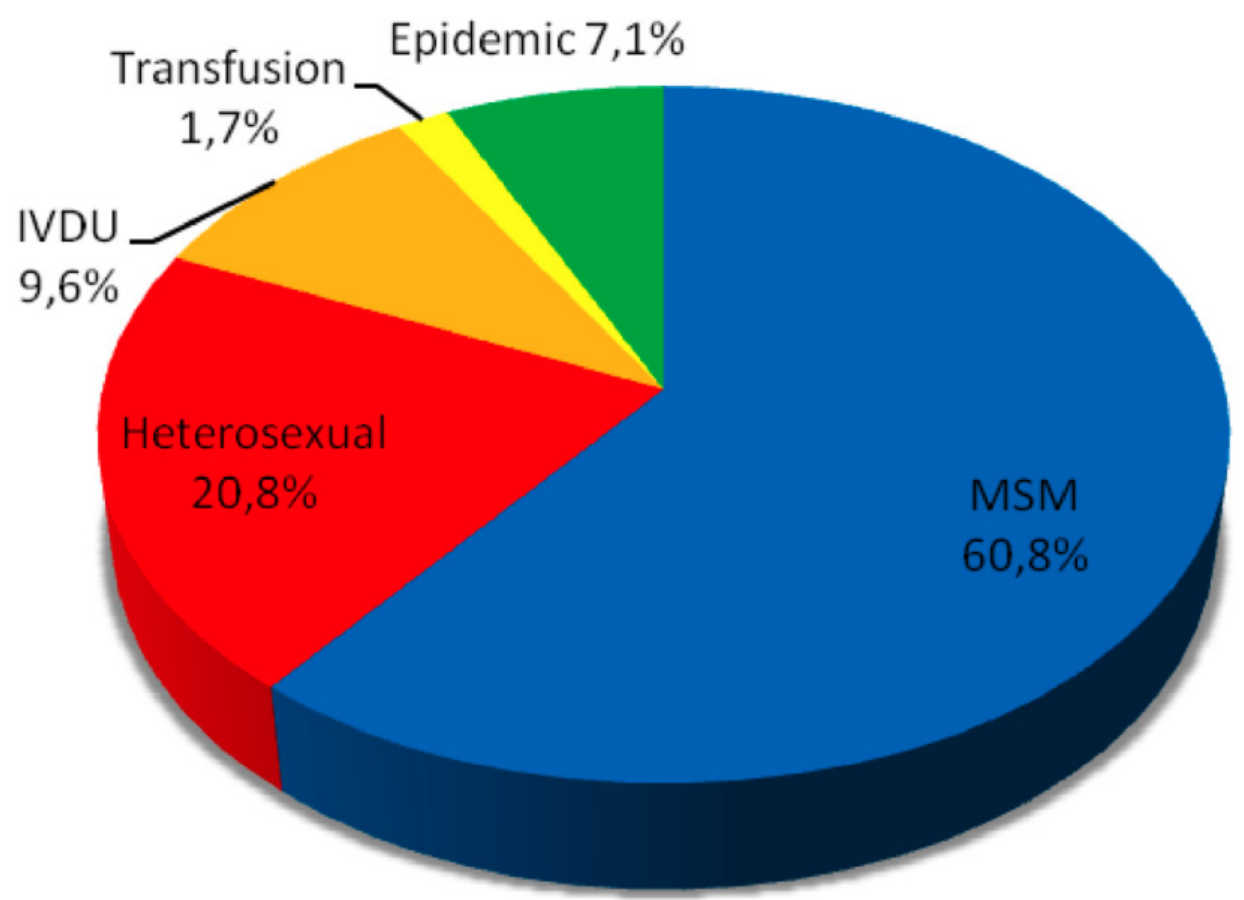

Fig. (4). Risk of infection with HIV in the patients included into the HIV-HEART Study. In 18 participants, the way of HIV-infection remained unclear. 


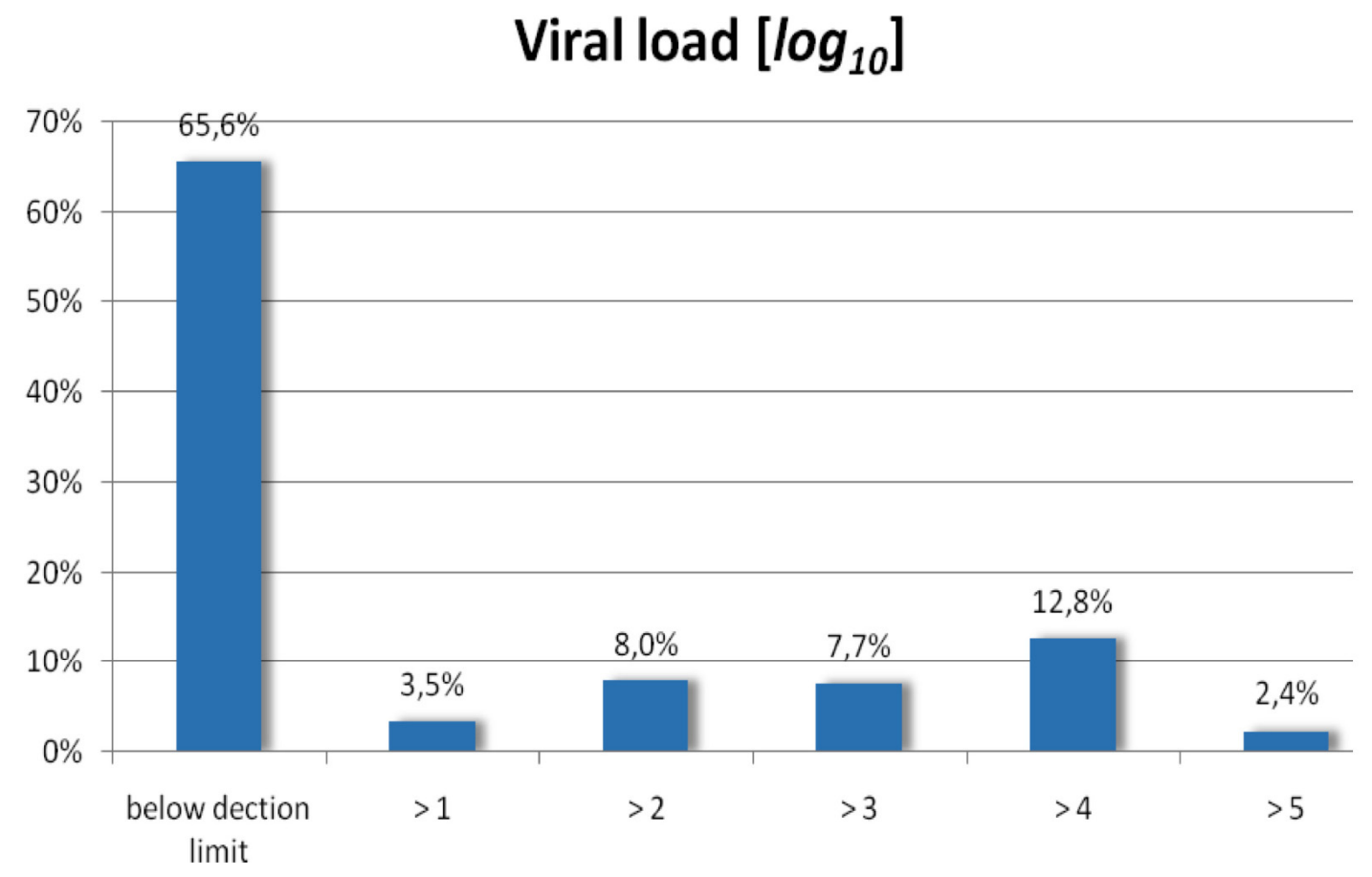

Fig. (5). Virus load of patients included into the HIV-HEART study.

\section{CDC classification}

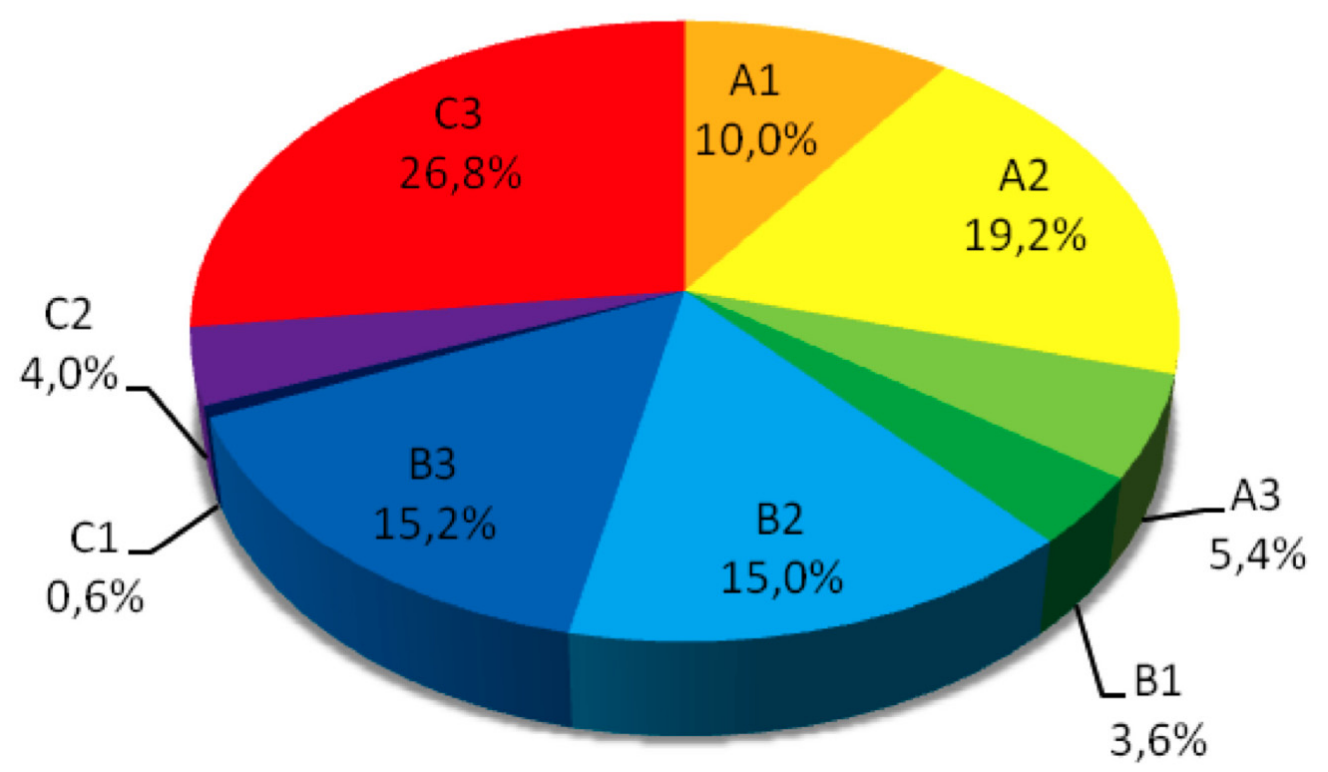

Fig. (6). Categorization of patients included into the HIV-HEART study due to the CDC-classification.

the included persons had a status $\mathrm{C}$ (AIDS level) in the CDCClassification. Infections with Hepatitis B and Hepatitis C were present in $30.5 \%$ and $10,5 \%$ respectively. However, liver cirrhosis was seen only in $1,3 \%$ of all patients.

\section{Antiretroviral Therapy}

Of all participants, $85,2 \%$ received antiretroviral therapy. Most of these patients received nucleoside-reverse transcriptase inhibitors (NRTIs) $(96,8 \%)$, followed by protease inhibitors (PIs) $(48,5 \%)$, and non-nucleosidereverse transcriptase inhibitors (NNRTIs) (45, 7\%). In 38, $9 \%$ the antiretroviral therapy contained 2 NRTI and 1 NNRTI, in 19, 5\% 2 NRTI were combined with 1 PI (+ Ritionavir) and 6, 7\% received 3 NRTIs. The entry inhibitor was given only to 8 patients $(1,2 \%)$ during baseline. Ritonavir was used as a booster in $36,9 \%$ of all patients with 
antiretroviral therapy. In more than $70 \%$, the virus load of treated patients, was under the lowest detection concentration of 50 copies/ml.

\section{DISCUSSION}

Even three decades after the first documented case [5], the HIV-infection is still a challenge of medicine. Current therapy with antiretroviral therapy provokes an effective blockade of virus replication and a decrease of opportunistic infections. As a result, a lower incidence of the acquired immunodeficiency syndrome (AIDS) increased survival rates in this patient population. However, mortality due to other diseases increased in HIV-infected patients in the last years. In particular the mortality due to cardiac diseases rose more than twice from $8 \%$ in the pre ART era up to now $22 \%$ [1] and further increase could be expected for the near future.

Associations between HIV-infection and a premature appearance of cardiac diseases were first suggested in the eighties [6-8]. A long list of potential agents, risk factors and triggers has been proposed previously [9-12]. The HIVHEART Study was launched to analyze the incidence and prevalence of cardiac diseases in HIV-infected patients.

As described in the results, we could achieve a linear recruiting of patients into the HIV-HEART Study. This quality criterion was reached by a mobile recruiting center, which accounts for equal inclusion rates and a high quality of the collected data. Even, the HIV-HEART Study did not reach patient-numbers of other international registers, the HIV-HEART Study is a prospective epidemiological trial, driven from a cardiology point of view, with high quality of acquired data and a low variance between the different participating centers. Most other studies performed cardiovascular analyses merely in a retrospective way after cardiac events occurred. Only a minority of previous HIVstudies performed cardiovascular tests prospectively. In most cases these tests are limited to an electrocardiogram. Exercise test or a comprehensive echocardiography are rare and the extensive diagnostic unique in this study.

Nevertheless, to generate transferable results the basic demographic data of the HIV-HEART Study cohort have to be comparable to the HIV-patient population in other industrialized countries and areas. The key parameters characterizing the included patients were presented in this publication.

The mean age in the present study was 44 years and about $83 \%$ were male. These data are comparable with information of the national health organization [13]. In the beginning of the epidemic spread, most infected patients were young men [5]. However, in the following decades, the characteristics of HIV-infected population changed. In particular the mean age increased since the onset of ART. A same trend was seen in the HIV-HEART Study, as nearly $40 \%$ of the participants were more than 45 years of age, even there had been only a minority of around $15 \%$ of patients which were aged 56 years or more. Furthermore, the duration living with HIV-infection increases. In our study, the life span between the initial diagnosis and inclusion into the study was 7, 6 years.

But the HIV-infected population is not only characterized by age, gender and duration of the disease. The way of infection is one of the main parameter of a HIV-infected cohort. However, these results of our study also correspond with the documented ways of HIV-infection in most industrialized countries $[13,14]$.

Even if a variety of key parameters are similar, not all of our baseline and demographic data are equivalent to other studies. Compared with the data of the D:A:D - Study [2] and the Swiss Cohort Study [15] the body mass index (BMI) and the blood pressure values were slightly increased by comparable age distribution. Nevertheless, the analysis of the fundamental characteristics of the participants in the HIV-HEART Study demonstrate the comparability of the included patient population with the data of national registers of HIV-infected citizens or international cohort registers in industrialized countries.

\section{CONCLUSION}

The HIV-HEART Study designed and performed to the regulations of prospective, multicenter trials, will be able to yield trustworthy data on HIV-associated diseases. The results from the HIV-HEART study will help to define whether cardiac diseases will play a major role in a general population of HIV-infected patients.

Trial registration: Clinical Trials NCT01119729

\section{ACKNOWLEDGEMENT}

The HIV-HEART study is part of the German Heart Failure Network and supported by the sponsorship of the Federal Ministry of Education and Research Germany (Bundesministerium für Bildung und Forschung). We also thank the members of the Competence Network for HIV/AIDS Germany supporting the present trial.

\section{REFERENCES}

[1] Crum NF, Riffenburgh RH, Wegner S, et al. Triservice AIDS Clinical Consortium. Comparisons of causes of death and mortality rates among $\mathrm{HIV}$-infected persons: analysis of the pre-early and late HAART eras. J Acquir Immune Defic Syndr 2006; 41: 194200.

[2] Friis-Møller N, Reiss P, Sabin CA, et al. Class of antiretroviral drugs and the risk of myocardial infarction. N Engl J Med 2007; 356: 1723-35.

[3] Neumann T, Esser S, Potthoff A, et al. HIV-HEART Study Investigative Group: Prevalence and natural history of heart failure in outpatient HIV-infected subjects: rationale and design of the HIV-HEART study. Eur J Med Res 2007; 12: 243-8.

[4] World Health Organization (WHO). Obesity: preventing and managing the global epidemic. Report of a WHO consultation. World Health Organ Tech Rep Ser 2000; 894: 1-253.

[5] Centers for Disease Control (CDC): Pneumocystis pneumonia. Morb Mortal Wkly Rep 1981; 30: 250-2.

[6] Corboy JR, Fink L, Miller WT. Congestive cardiomyopathy in association with AIDS. Radiology 1987; 165: 139-41.

[7] Paton P, Tabib A, Loire R, Tete R. Coronary artery lesions and human immunodeficiency virus infection. Res Virol 1993; 144: 225-31.

[8] Tabib A, Greenland T, Mercier I, Loire R, Mornex JF. Coronary lesions in young HIV-positive subjects at necropsy. Lancet 1992; 340: 730 .

[9] Neumann T, Kondratieva J, Eggebrecht H, et al. Coronary heart disease associated with the use of highly active antiretroviral therapy (HAART). A case report and review. Herz 2005; 30: 5049.

[10] Ford ES, Greenwald JH, Richterman AG, et al. Traditional risk factors and D-dimer predict incident cardiovascular disease events in chronic HIV infection. AIDS 2010; 24(10): 1509-17. 
[11] Worm SW, De Wit S, Weber R, et al. Diabetes mellitus, preexisting coronary heart disease, and the risk of subsequent coronary heart disease events in patients infected with human immunodeficiency virus: the Data Collection on Adverse Events of Anti-HIV Drugs (D:A:D Study). Circulation 2009; 119(6): 805-11.

[12] Worm SW, Sabin C, Weber R, et al. Risk of myocardial infarction in patients with HIV infection exposed to specific individual antiretroviral drugs from the 3 major drug classes: the data collection on adverse events of anti-HIV drugs (D:A:D) study. J Infect Dis 2010; 201(3): 318-30.
[13] Robert-Koch-Institute. Epidemiological Bulletin October 2007, http:// www.rki.de

[14] Friis-Møller N, Sabin CA, Weber R, et al. Data Collection on Adverse Events of Anti-HIV Drugs (DAD) Study Group. Combination antiretroviral therapy and the risk of myocardial infarction. N Engl J Med 2003; 349: 1993-2003.

[15] Glass TR, Ungsedhapand C, Wolbers M, et al. Swiss HIV Cohort Study: Prevalence of risk factors for cardiovascular disease in HIVinfected patients over time: the Swiss HIV Cohort Study. HIV Med 2006; 7: 404-10.

(C) Neumann et al.; Licensee Bentham Open.

This is an open access article licensed under the terms of the Creative Commons Attribution Non-Commercial License (http://creativecommons.org/licenses/by$\mathrm{nc} / 3.0 /$ ) which permits unrestricted, non-commercial use, distribution and reproduction in any medium, provided the work is properly cited. 